\title{
Germline cells in ovarian surface epithelium of mammalians: a promising notion
}

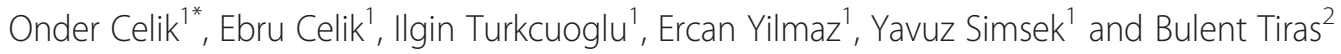

\begin{abstract}
It is a long held doctrine in reproductive biology that women are born with a finite number of oocytes and there is no oogenesis during the postnatal period. However, recent evidence challenges this by showing the presence of germ line stem cells in the human ovarian surface epithelium (OSE), which can serve as a source of germ cells, and differentiate into oocyte like structures. Postnatal renewal of oocytes may have enormous therapeutic potential especially in women facing the risk of premature ovarian failure idiopathically or iatrogenically after exposure to gonadotoxic chemotherapy and radiation for cancer therapy.

This article reviews current knowledge on germ line stem cells in human OSE.
\end{abstract}

Keywords: Human, Ovarian surface epithelium, Stem cells, Germ line cells, Pluripotency, Oocyte-like cells

\section{Background}

Ovarian surface epithelium (OSE) cells differentiate from peritoneal mesothelial cells through their transformation from mesenchymal into epithelial cells [1]. The function of healthy OSE is regeneration and repeated proliferation of cells after ovulation during the reproductive period. Since apparent paucity of significant functions, OSE has received less attention compared to other components of ovarian tissue. The role of OSE in the pathogenesis of epithelial ovarian carcinoma is well established; however, its role in human oogenesis has remained controversial [2-4]. It has been reported that OSE is the source, at least partially, of granulosa cells in the human, and expresses stem cell markers of both epithelial and mesenchymal origin $[3,5]$.

In 1917, Kingery [6] did explain the concept of follicular regeneration from the surface epithelium of postnatal mouse ovary first before mentioning Simkins [7]. In their pioneering work Simkins et al. described the natural role of OSE as supplying germ cells during the entire fetal period [7]. The role of human OSE as a source of oocytes during intrauterine life has been confirmed by scanning and transmission electron microscopy [8]. Recently oogonial stem cells have successfully been isolated from ovaries

\footnotetext{
*Correspondence: onder.celik@inonu.edu.tr

'Department of Obstetrics and Gynecology, Inonu University, Medical

Faculty, Malatya, Turkey

Full list of author information is available at the end of the article
}

of neonate and adult mice as well as from human ovaries $[9,10]$. However, these studies have received some criticism. Byskov et al. later demonstrated that bromodeoxyuridine (BrdU) negative oocytes could be present in female mice after injection of BrDU [11]. Additionally, statistical and mathematical studies involving ovarian reserve found no evidence to support the occurrence of neoogenesis in adult mammals $[12,13]$. Regardless, OSE is physiologically much more complex than that would be predicted from its inconspicuous appearance. The present review summarizes current knowledge on OSE as a source of neo-oogenesis.

\section{Ovarian surface epithelium as a regenerative layer of germinal epithelium}

A surprising phenomenon described by Johnson et al. who has demonstrated that the mouse ovary is capable of producing new oocytes and follicles from germ line stem cells (GSC) present in OSE after depletion of ovarian cells by chemotherapy [9]. Moreover, they also showed the presence of presumptive mitotically active GSC, expressing VASA protein specific to germ cells, in or close to OSE from juvenile and adult mice. Concerning the origin of new germ cells in mammalian species and humans, the same group proposed that germ line stem cells could be present within the bone marrow and peripheral blood [10]. The follicles containing immature and mature bona fide oocytes, expressing germ cell and 
oocyte-specific markers, were shown to be formed after bone marrow transplantation irrespective of BMT interval in adult mice treated with chemotherapy. This study has been widely disputed and, several researchers have challenged their findings. A recent study by Santiquet et al. found that new oocytes could be produced neither after BMT nor grafted bovine embryonic ovarian cortex in PU.1 mice and severe combined immunodeficiency (SCID) mice, treated with chemotherapeutic agents [14]. However, the fertility of SCID mice, exposed to chemotherapeutic agents, has been found to be improved after bone marrow transplantation. Thus, the authors have suggested that, despite chemotherapeutic agents, sparing follicles could be restored of self-tolerance of ovarian antigens; thereby, BM cells may have beneficial effects on ovarian physiology.

One morphological study, supporting oocyte renewal, conducted by Kerr et al. reported that despite a rapid decline in the number of primordial follicles per ovary, as measured by unbiased stereological methods, during the first week of postnatal life, the primordial follicle count remained constant and stable during the period between the 7th and 100th days of life in C57BL/6 mouse [15]. Further, they have also demonstrated the presence of dividing cells in OSE by using antibodies against proliferating cell nuclear antigen and germ cell nuclear antigen in prepubertal mouse.

The concept of follicular renewal in postnatal mouse ovary triggered a significant deal of debate. Eggan et al. failed to demonstrate production of any mature oocytes derived from blood born progenitor germ cells following bone marrow transplantation in parabiotic model and also indicated that a few oocytes could rescue from chemotherapeutic agents [16]. In line with previous report, Liu et al. in 2007 reported a conflicting result that either expression of SCP3 marker for meiosis or oogenesisassociated mRNAs for SPO11, PRDM9, SCP1, TERT and NOBOX could not be detected in adult human ovary [17]. Nevertheless, the authors concluded that the presence of a few numbers of cells with mRNA in human ovaries could not be excluded in the study. The result of that study conducted by Liu et al. was in accordance with a subsequent study using histology and immunohistochemical staining for oogonia cell specific markers (C-KIT, SSEA4, NANOG and OCT4 and the testis tumor related MAGE-A4) on the cortex and medulla of young female ovary, from fetal period to adulthood $[17,18]$. That study has indicated that there were no oogonia stained with pluripotent immunohistochemical markers after the age of 2 years. The authors have doubted that these findings, however, do not rule out either the possibility of OSE cells de novo transformation into multipotent stem-like cells in postnatal human ovary. Latterly, Kerr et al., using same unbiased, assumption free fractionator method, assessed more ovaries to enhance their previous findings [19]. In that study, 97 ovaries were obtained from mice aged 3-300 days old that were exposed to gonodatoxic agents, or whole-body ionizing radiation. The observations revealed that these ovaries were germ cell nuclear antigen negative and no evidence of regeneration of primordial follicle numbers after either expose to chemotherapeutic agents or ionizing radiation. Moreover, morphological and immunochemical analysis was confirmed by stereological analysis of treated ovaries. These recent observations reported by Kerr et al. support the belief that a finite number of oocytes are formed during fetal period and that no new oocytes are generated after the pool of primordial follicles is established [19].

\section{Expression of stem cell and germ cell markers in OSE}

Observations in adult human ovaries raised a question whether OSE cells express the specific markers for stem and germ cells. Telomerase is a ribonucleoprotein that synthesizes telomere repeats to chromosome ends. It is involved in maintaining telomere length in germ line tissues, which plays an essential role in replicative life span [20]. Wright et al. detected telomerase activity in germ line tissue and stem and cancer cells from fetal, neonatal, and adult testes and ovaries [21]. Subsequently, Kinugawa et al. found that telomerase activity is also present in normal ovaries, but it was decreased with age [22]. Their sample included five women with premature ovarian failure (POF); two of who were categorized as having follicular dysfunction by the virtue of having a high number of primordial follicles present in their ovaries (mean 11.8 follicles per medium power field) while remaining three women had genuine follicle depletion (0.03 follicles per medium power field). Further, POF and postmenopausal women showed either high or low telomerase activity in the ovarian surface cell layer in the POF group, but showed high telomerase activity in postmenopausal group just after scrapping of OSE.

Parrott et al. has shown that human and bovine OSE cells express high levels of c-kit receptor and kit-ligand/ stem cell factor (SCF) proteins in vitro, and SCF gene expression is significantly increased in cultured OSE cells [23]. A study on gene expression profiling of OSE from women with healthy ovaries or with serous papillary ovarian adenocarcinoma reported that while normal OSE expressed genes leading to adult stem cell maintenance and pluripotency at a high rate, OSE cells from adenocarcinoma samples expressed these genes at very low levels or did not at all [24]. Recent study noted that human epithelial stem-like cells are located in the distal fimbriated part of fallopian tubes; further, these cells are able to express stem-like markers, which may play a role in the initiation of serous tumors in ovary $[25,26]$. 
Vrant-Klun et al. reported the presence of primitive oocyte like cells, which expressed specific markers for pluripotency, in OSE from a woman with ovarian carcinoma [27]. This observation led to the hypothesis that stem cells located in OSE may have, in fact, pluripotent (or totipotent?) capacity and can give rise to formation of new oocytes. Parallel to these studies, Bukovsky et al. has shown that OSE cells could be the bipotent source for germ and granulosa cells $[28,29]$.

The in vivo observations in adult human ovaries indicated that some OSE stem cells were able to convert into germ cells by asymmetric division [30-33]. Some experimental evidence has been indicated by Bukovsky et al. confirmed the existence of oocyte-like cells in cultured OSE cells, which was scrapped from postmenopausal women [34,35]. Immunohistochemistry analysis indicated that the oocytes derived from OSE expressed VASA and deleted azoospermia-like (DAZL) [36].

Later on Zhang et al. confirmed aforementioned observations [37]. The authors used an enhanced green fluorescent protein transgenic model to evaluate the expression of stem and germ cell markers in adult murine ovaries. They were able to demonstrate the presence of pluripotent surface markers (OCT3/4, MVH, SCF-R, and SSEA-1) as well as meiotic markers (DMC1 and SCP3) in specific cells collected from the periphery of adult murine ovary. Importantly, these cells were distinct from ovarian follicles. Based on their observations, Zhang et al. suggested that these cells maintain a mixed cluster of committed stem cells and also a transitional stage of GSC that may be capable of proliferation and differentiation [37]. Following this study on mice, Vrant-Klun et al. demonstrated evidence of presence of putative stem cells (PSCs), which expressed characteristic markers for pluripotency, in the OSE layer of postmenopausal women and women with POF [38]. The authors also detected a pluripotent pattern of gene transcription in OSE of adult human by reverse transcription-polymerase chain reaction (RT-PCR) analysis. Another study conducted by the same group has provided further insight into the presence of germ stem cells in the OSE of postmenopausal women [39]. In this study, rare putative stem cells with germline characteristics were isolated from OSE of postmenopausal human ovaries devoid of oocytes.

A recent study from our groups used a porcine small intestine submucosa (SIS) patch to repair surgically induced damage to ovarian surface in a rabbit model [40]. We were able to demonstrate development of follicular structures around and in the SIS graft starting from the 28th week post surgery. In addition, noticeable PCNA staining was found in oocytes arrested in the meitotic phase.

A recent study by Parte et al. involving OSE from postmenopausal women and other mammalian species provided further support for the presence of PSCs [41]. They found small round PSCs, which clearly stained by DAPI, spontaneously increased in size and differentiated into oocyte like structures, and these oocyte like structures were surrounded by zona pellucida-like and blastocyst like structures in OSE cultures. In addition to the expression specific markers for pluripotency by the oocyte-like cells obtained post-culture, pluripotent gene transcripts were also detected by RT-PCR in OSE scrapings from humans and other mammalian species. Further evidence of the presence of PSC in OSE was provided by another study involving women with POF. OSE cells obtained by scrapping ovaries devoid of oocytes were cultured in a medium containing follicular fluid [42]. Primitive oocyte-like cells positively stained for alkaline phosphatase and expressed markers of pluripotency (SOX-2 and SSEA-4) as well as the typical genes (OCT4A, SOX-2, NANOG, NANOS, STELLA, CD9, LIN28, KLF4, GDF3, and MYC) for pluripotent stem cells. In view of their findings, the investigators concluded that the PSCs exist in OSE of women with POF.

It becomes relevant to refer the last published study here. Bhartiya et al. showed that the gonadotropininduced pluripotent very small embryonic stem cells (VSELs) (increased expression of Oct-4A, Nanog) underwent proliferation (increased PCNA staining and Oct4A expression) and differentiation (increased expression of stella, fragilis, total Oct-4, Vasa and MVH) [43]. Further, the differentiating oocyte undergoes to meiosis and exhibits germ cell markers like Stra-8, Scp3 and Dmc1; besides the developing oocytes surrounded by granulosa like cells assemble primordial follicule in vitro. The study demonstrated that upregulation of follicular stimulating hormone receptor through gonadotropin administration to adult mouse leads to increased pluripotent stem cell activity in the OSE, related to meiosis and also exhibits several germ cell markers in vitro. In view of these findings, that study proposed that epithelial mesenchymal transition gives rise to granulosa like cells whereas VSELs differentiate to form oocytes.

At this juncture, it is crucial to consolidate the various studies, thus a clear understanding emerges. Table 1 is a list of different studies on ovarian surface epithelium.

\section{Very small embryonic like putative stem cells in mature mammalian ovary}

Previous reports have proposed that the ovary of adult mammalian consists of two different populations of stem cells, termed as VSELs, and slightly larger ovarian germ stem cells (OGSCs) [41]. Ratajczak et al. isolated small stem cells with a diameter of 2-4 micrometers from murine bone marrow. These cells expressed characteristic markers for embryonic, epiblast stem and primordial germ cells (PGCs) [49]. Ratajczak et al. suggested VSELs 


\section{Table 1 Pivotal observations advanced in support of presence of stem cells in ovarian surface epithelium of} mammalian species

\begin{tabular}{lll}
\hline Published studies & Study observations & Interpretation of published data \\
\hline Johnson et al., (2004) [9] & $\begin{array}{l}\text { Highly expression of early meiotic markers in surface } \\
\text { epithelium of postnatal ovary. Formation of chimeric } \\
\text { follicles after transplantation of wild type ovarian tissue } \\
\text { onto ovary of GFP expressing transgenic mice. }\end{array}$ & $\begin{array}{l}\text { The regeneration of de novo new primordial follicle } \\
\text { suggest that oocytes may arise from a rare uncharacterized } \\
\text { circulation of cells, which are present in BM and peripheral }\end{array}$ \\
$\begin{array}{lll}\text { Bohnson et al. (2005) [10] } \\
\text { Bone marrow serves as a source of germ stem cells in } \\
\text { adult mammalian, which can be transported by peripheral }\end{array}$ & $\begin{array}{l}\text { Induction of oocyte atresia by gonadotoxic agents possibly } \\
\text { mobed VSELs from BM to enter peripheral circulation }\end{array}$
\end{tabular}

Bukovsky et al. (2004, 2005, 2009, 2011, 2012)

Virant-Klun et al. (2008, $2008,2011)[38,39,42]$

Zhang et al. (2008) [37]

Niikura et al. (2009) [44]

Zou et al. (2009) [45]

Parte et al. (2011) [41]

Santiquet et al. (2012) [11] $[43,46]$

White et al. (2012) [47]

Bhartiya et al. (2012) [29,30,33-35] blood to the ovaries.

Putative germ cells within the OSE of postnatal ovary differentiate from mesenchymal progenitors in the ovarian tunica albuginea. Large oocyte-like cells expressing zona pellucida proteins are formed in set up cell cultures from scrapped OSE. Reproducible, oocyte-like cells from OSE of ovaries subjected to ovotoxic agents.

VSEL in OSE able to generate oocyte-like cells in vitro. These cells expressed pluripotent specific markers. Oocytes derived from VSEL cells de novo underwent parthenogenetic activation to produce blastocyst-like cells with neuronal phenotype and embryoid bodies. These structures expressed pluripotent specific markers Oct-4, Oct-4 A, Nanog, Sox-2, and TERT.

Germ cell markers (OCT-3/4, MVH, SCF-R and SSEA-1) and meiotic markers (DMC1 and SCP3) within specific cells aggregated from the periphery of adult murine ovaries.

Aged mouse ovaries are able to form premeiotic germ cells (high expression of Stra8 and Daz1), when transfer into a young ovarian environment, they can differentiate into oocytes (increased expression of Oct4-GFP, c-kit, Mvh and SSEA-1).

MVH positive FGSCs isolated from adult mice ovaries and retained in vitro for months. These cells after transplantation into atretic ovaries of recipient mice by gonadotoxic agents produced new follicle, which fertilized and gave rise to offspring carrying the same gene as their mothers.

Two different populations of putative stem cells detected in scrapped OSE of postnatal mammalian ovary, namely VSELS and slightly larger ovarian stem cells termed as OGSCs. VSELs expressed nuclear Oct-4 but the OGSCs exhibited cytoplasmic Oct-4. Pluripotent specific markers were detected in human and sheep OSE. After 3 weeks of OSE cultures, oocyte-like cells expressing c-kit, DAZL, VASA and ZP4 emerged

Chemotherapy sterilized SCID mice could not generate new oocytes after BMT but fertility of mice has improved.

Gonadotropin induced pluripotent VSELs underwent proliferation and differentiation (increased expression of stella, fragilis, total Oct-4, Vasa and MVH). Differentiating oocyte undergoes to meiosis and exhibits germ cell markers like Stra-8, Scp3 and Dmc1.

Purified rare mitotically active cells features in both mouse and human ovaries, generated oocytes (diameter of $35-50$ micron) per se and entered into meiotic division. Injection of GFP transfected human OSCs into the human ovarian cortical tissue strips resulted in generation of GFP expressing follicles one-two weeks after xenografting these strips into diabetic SCID mice. Successfully purified rare cell surface DDX4 positive OGCs from cortical tissue of reproductive aged adult human ovaries.
These results are in agreement with previous data that stem cells in OSE are able to produce oocyte-like structures $[38,39]$

Presence of rare putative stem cells with germline characteristics in the OSE of postmenopausal women accorded the initial finding of existence of GSC in adult mouse ovary [9].

Mixed cluster of committed stem cells and also a transitional stage of GSC that may retain the capacity of proliferation and differentiation.

The concept of rapid decline in the number of follicles being mainly due to decreased oocyte renewal rather than to an accelerated loss.

This study purified the initial cells expressing germ cell markers, but not early stem cell markers.

VSELs are totipotent to pluripotent in nature and form OGSCs, which are able to further differentiate into oocytelike and neuronal-like structures.

Despite ovarian atresia by chemotherapeutics, sparing follicles could be restored of self-tolerance of ovarian antigens; thereby, BM cells possibly initiate an endocrine/ paracrine signal that improves the functionality of ovarian niche.

Close association of developing oocytes with mesenchymal cells in vitro, which is produced by epithelial to mesenchymal transition of the OSE suggested that new oocytes surrounded by granulosa-like cells assemble as primordial follicles in the OSE of adult ovary.

The study showed that rare cells (expression of cell-surface of DDX4) exist in the OSCs of adult human. Production of chimeric follicle in vitro and more importantly in vivo when injected into cortical tissue strips from human ovaries. 


\section{Table 1 Pivotal observations advanced in support of presence of stem cells in ovarian surface epithelium of mammalian species (Continued)}

\begin{tabular}{|c|c|c|}
\hline Hayashi et al. (2012) [48] & $\begin{array}{l}\text { After transplantation of both female PGCs and embryonic } \\
\text { gonadal somatic cells under ovarian bursa or kidney capsules } \\
\text { of recipient mice, induced-ESCs transformed into PGCLCs, } \\
\text { which contributes to oocyte-like cells in reconstituted ovaries. } \\
\text { These cells matured into fully functional germinal vesicle stage, } \\
\text { including multiple layers of granulosa and theca cells in vivo. }\end{array}$ & $\begin{array}{l}\text { This study demonstrated that possibility of reconstitute } \\
\text { female germline development in vitro, not only } \\
\text { in mice, but also in humans. }\end{array}$ \\
\hline
\end{tabular}

were pluripotent stem cells, which were deposited during gastrulation and organogenesis in the mammalian embryo [49]. It has been shown that these cells could differentiate into all three-germ-layer cells in in vitro culture [50]. VSELs also expressed several characteristic markers for PGCs (fetal-type alkaline phosphatase (AP), octamer-binding transcription factor 4 (Oct-4), SSEA-1, CXCR4, Mvh, Stella, Fragilis, Nobox, Hdac6). These findings may also suggest a possible close association of those cells with epiblast-derived PGCs. They concluded that, VSELs in adult organs declines with age, and their ability to form spheres containing PGS decreases with time. These observations could explain more efficient regeneration in younger adults compared to older ones.

These observations directed attention towards the possible existence of VSELs in human OSE. Virant-Klun et al. isolated VSELs from OSE obtained from 21 postmenopausal women whose ovaries contained no follicles [39]. Fascinatingly, VSELs were transformed into oocytelike cells and parthenogenetic blastocyst-like structures in vitro culture. More importantly, these oocyte-like cells exhibited positive staining for some pluripotent embryonic stem cell markers such as SSEA-4, Oct-4, Sox-2 and NANOG. Recently, these reported findings have been confirmed by Parte et al. [41]. The presence of VSELs with cytoplasmic OCT-4 in ovaries, which can be isolated by scrapping of OSE spontaneously differentiated into oocyte-like structures in vitro. Additionally, this group has also shown slightly larger cells with cytoplasmic OCT-4 that were defined as OGSCs. The presence of two different populations of stem cells was confirmed in adult mouse ovaries by using both immune-localization and quantitative polymerase chain reaction analysis [46].

Recently, we have cultured the ovarian surface epithelium of postmenopausal women and POF patients whom their OSE layer was confirmed under inverted microscope, 400 (unpublished data). On the day 7 of the OSE cell culture, oocyte-like cells with a diameter of approximately $10-15 \mu \mathrm{m}$ were developed among proliferating small cells-putative stem cells. (Figure 1A - D). The developed oocyte-like cells, resembling a small bubble-

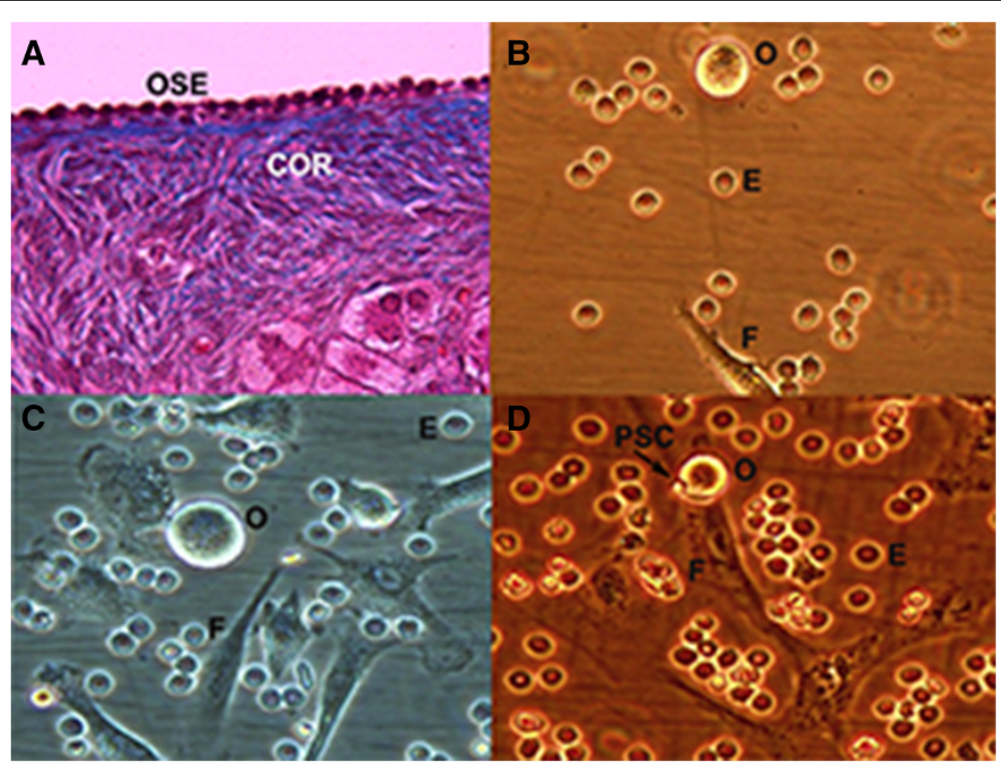

Figure 1 Ovarian surface epithelium (OSE) histology and oocyte-like cells developing among putative stem cells in the OSE culture. (A) OSE layer with no follicles and oocytes in the ovarian cortex (COR) after Masson's trichrome staining of the ovarian section (light microscope, magnification 40X). (B, C) Different types of cells including erythrocyte (E), fibroblast (F), oocyte-like cells ((0), 10 - 15 um) (inverted microscope, 400). (D) Oocyte-like cell $(10 \mu \mathrm{m})$ developing in close contact with putative stem cells (PSC) and fibroblasts on day 7 of culture (inverted microscope, 400) 
like structure, were developed from putative stem cells, and mostly grew attached to the fibroblasts. On the other hand, we noted that these cells did not express any germ line cell markers in the immunohistochemical examination.

\section{Production of offspring from OSE cells}

The observations of some OSE cells transition into oocyte like cells have raised a question whether such potential can also be used to produce offspring from OSE cells. The initial study by Bukovsky et al. demonstrated that some oocyte like cells derived from OSE cells differentiated de novo into parthenogenetic blastocyst and embryo-like structures, which expressed DAZL [30,51]. These observations supported by Virant-Klun et al. showed that under certain conditions, in vitro isolated cells from OSE per se had the ability to produce oocytes or oocyte-like cells, which also could undergo parthenogenetic development to generate blastocyst-like structures $[38,39]$. Interestingly, Niikura et al. demonstrated high expression of the premeiotic marker Stra8 and Daz1 in the ovary of aged female mice, despite the absence of oocytes [44]. Following grafting ovarian tissue harvested from aged female germline specific green fluorescent protein (GFP) expressing mice (PE-Oct4-Gfp or TgOG2 transgenic) into the ovarian bursal sac of young adulttype female recipients, a small number of GFP-positive germ cells, as immature follicles and co-expressing the primordial oocyte marker NOBOX, were detected. However, the number of immature follicles in the ovary of the young adult mouse, exposed directly to an aged systemic environment, was decreased. These observations support the concept of rapid decline in the number of follicles being mainly due to decreased oocyte renewal rather than to an accelerated loss. In line with the previous findings, Zou et al. established a neonatal female germline stem cell (FGSC) line positive for mouse vasa homologue protein $(\mathrm{MVH})$ from 5 day old and adult C57BL/6 wild-type and C57BL/6CD-1 F1 hybrid mice $[9,45]$. Following in vitro culture, retroviral infection with GFP and bromodeoxyuridine labeling FGSCs were transplanted into ovaries of chemically sterilized sixweek-old C57BL/6CD-1 F1 hybrid females. Transplanted cells underwent oogenesis demonstrated high telomerase activity and the mice delivered offspring carrying the GFP gene. Recently Pacchiarotti et al. further illustrated the validation of cell lines as ovarian germ line stem cells [52]. They reported the isolation of cells containing the putative stem cells from the OSE of neonatal OG2 mice. Following aggregation with granulosa cells, formation of "embryonic bodies" containing differentiated derivatives of the three germ layers and production of early stage oocytes were demonstrated during culture.
A recent intriguing study using an antibody against DEAD [Asp-Glu-Ala-Asp] box polypeptide 4 (DDX4) coupled with a fluorescence-activated cell sorting (FACS) reported the presence of purified rare mitotically active cells with germ line specific gene expression features in both mouse and human ovaries [47]. These cells were able to spontaneously form oocytes with an approximate diameter of $35-50$ micron. Presence of oocyte specific markers was confirmed. Further germ cell specific proteins (DNA recombinase dosage suppressor of mck1 homolog (DMC1) and synaptonemal complex protein 3 (SYCP3)) necessary for progression of meiotic recombination were identified in these cells, indicating entry to meiotic division. Chromosomal DNA content analysis revealed diploid (2n) and haploid (1n) cell populations in the in vitro human OSC cultures. Injection of GFP transfected human OSCs into the human ovarian cortical tissue strips resulted in generation of GFP expressing follicles $1-2$ weeks after xenografting these strips into non-obese diabetic-severe combined immune-deficient mice. Eventually, the authors have successfully purified rare cell surface DDX4 positive oogonial stem cells from cortical tissue of reproductive aged adult human ovaries. These cells were able to develop and demonstrate both mitotic and meiotic activity. They produced oocytes in vitro, and more importantly in vivo when injected into cortical tissue strips from human ovaries.

Similar perspective has also been proposed by other group [48]. In combination of female PGCs with embryonic gonadal somatic cells were transplanted under ovarian bursa or kidney capsules of recipient mice in vitro for oogenesis. After epithelial stem cells (ESCs) were induced to transform into primordial germ cell-like cells (PGCLCs), histological sections revealed that PGCLCs contribute to oocyte-like cells in reconstituted ovaries in vitro and further matured into fully functional germinal vesicle stage, including multiple layers of granulosa and theca cells thereafter transplantation in vivo [48]. Combined with previous studies, the observations of this study further demonstrated that it is possible to reconstitute female germ line development in vitro in mice as well as other mammalian species including humans.

\section{Conclusion}

The function of OSE during postnatal period in mammalian species remains elusive. The questions of whether germ line stem cells exist in the surface epithelium of the adult human ovaries and if they do exist, whether they can generate oocytes need to be precisely addressed. However, in the concept of reproductive medicine, infertile patients with POF, poor responders, women undergoing gonadotoxic treatment before completion of childbearing, or those young women with isolated high serum FSH levels are of interest; thus, there is no doubt 
that any potential approach to reform their oocytes would be of great improvement. OSE has been indicated to be a niche of oocytes during the embryonic life in human beings $[8,53]$. Accumulating data are present regarding to increasing evidence of the existence of putative GSC within adult mammalian OSE. A small number of PGCs/ oogonia or PGC-derived VSELs with GSC characteristics can be possibly retained in postnatal and adult ovary, and under certain conditions, they may resume mitosis, enter meiosis and form new oocytes. Therefore, the presence of ovarian stem cells in the OSE of women with ovarian failure or diminished ovarian reserve are an essential concept to be investigated further in terms of their possible regenerative capacity in adult mammalians. In vitro OSE cultures would be beneficial models to put forth the molecular and cellular functions of OSE in entire women population including fertile and infertile. In general agreement, the presence of ovarian stem cells in the OSE appears to be evident. Considering these striking observations reported by aforementioned studies, OvaScience conducts a Phase I study in which mitochondria of oocytes will be isolated from OSCs of a woman undergoing to IVF and then, these isolated cells will be autologously injected into the oocytes of the same patient [54]. If the researchers achieve the expected results of that trial, compromising increased egg viability, embryo development and success rate of IVF, the evidence will provide an essential prospect for the management of infertile women who have been seeking for a child for years.

\section{Abbreviations}

BM: Bone marrow; BMT: Bone marrow transplant; C-kit: Tyrosine kinase receptor for stem cell factor; DAZL: Deleted azoospermia-like; DDX4: DEAD [Asp-Glu-Ala-Asp] box polypeptide 4; DMC1: DNA recombinase dosage suppressor of mck1 homolog; ESCs: Epithelial stem cells; FGSC: Female germline stem cell; FACS: Fluorescence-activated cell sorting; GCS: Germ line stem cells; GDF3: Growth differentiation factor-3; GFP: Green fluorescent protein; KLF4: Krueppel-like factor 4; Mage-A4: Melanoma antigen-4; MVH: Mouse vasa homologue protein; NANOG: Homeobox gene transcription factor; NOBOX: Newborn ovary homeobox; OCT4: Octamer binding transcription factor 4; OSE: Ovarian stem cell; POF: Premature ovarian failure; PGCs: Primordial germ cells; SOX2: Sex determining region Y box 2; SSEA4: Stage-specific embryonic antigen-4; SYCP3: Synaptonemal complex protein 3; TgOG2: Transgenic GFP-expressing mice; VSELs: Very small embryonic-like cell(s).
\end{abstract}

\section{Competing interests}

The authors declare that they have no competing interests.

\section{Authors' contributions}

OC: 1) has made substantial contributions to conception and design, 2) has been involved in drafting the manuscript, and 3) have given final approval of the version to be published. EC: 1) has made substantial contributions to conception and design, 2) has been involved in drafting the manuscript or revising it critically for important intellectual content. IT: 1) has made substantial contributions to conception and design, 2) revising it critically for important intellectual content. EY: revising it critically for important intellectual content. YS: revising it critically for important intellectual content. BT: revising it critically for important intellectual content. All authors read and approved the final manuscript.

\section{Author details}

'Department of Obstetrics and Gynecology, Inonu University, Medical Faculty, Malatya, Turkey. ${ }^{2}$ Department of Obstetric and Gynecology, Acibadem University, School of Medicine, Istanbul, Turkey.

Received: 21 October 2012 Accepted: 14 December 2012 Published: 17 December 2012

\section{References}

1. Auersperg N, Edelson MI, Mok SC, Johnson SW, Hamilton TC: The biology of ovarian cancer. Semin Oncol 1998, 25:281-304.

2. Ahmed N, Thompson EW, Quinn MA: Epithelial mesenchymal interconversions in normal ovarian surface epithelium and ovarian carcinomas: an exception to the norm. J Cell Physiol 2007, 213:581-588.

3. Okamoto S, Okamoto A, Nikaido T, Saito M, Takao M, Yanaihara N, Takakura S, Ochiai K, Tanaka T: Mesenchymal to epithelial transition in the human ovarian surface epithelium focusing on inclusion cysts. Oncol Rep 2009, 215:1209-1214.

4. Zhu Y, Nilsson M, Sundfeldt K: Phenotypic plasticity of the ovarian surface epithelium: TGF-beta1 induction of epithelial to mesenchymal transition (EMT) in vitro. Endocrinology 2010, 151:5497-5505.

5. Byskov AR, Skakkebaek NE, Stafanger G, Peters H: Influence of ovarian surface epithelium and rete ovarii on follicle formation. J Anat 1977, 123:77-86.

6. Kingery HM: Oogenesis in the white mouse. J Morphol 1917, 30:261-316.

7. Simkins CS: Development of the human ovary from birth to sexual maturity. J Anat 1932, 51:465-505.

8. Motta PM, Makabe S: Germ cells in the ovarian surface during fetal development in humans. A three dimensional microanatomical study by scanning and transmission electron microscopy. J Submicrosc Cytol 1986, 18:271-290

9. Johnson J, Canning J, Kaneko T, Pru JK, Tilly JL: Germline stem cells and follicular renewal in the postnatal mammalian ovary. Nature 2004, 428:145-150.

10. Johnson J, Bagley J, Skaznik-Wikiel M, Lee HJ, Adams GB, Niikura Y, Tschudy KS, Tilly JC, Cortes ML, Forkert R, et al: Oocyte generation in adult mammalian ovaries by putative germ cells in bone marrow and peripheral blood. Cell 2005, 122:303-315.

11. Byskov AG, Faddy MJ, Lemmen JG, Andersen CY: Eggs forever? Differentiation 2005, 73:438-446.

12. Bristol-Gould SK, Kreeger PK, Selkirk CG, Kilen SM, Mayo KE, Shea LD, Woodruff TK: Fate of the initial follicle pool: empirical and mathematical evidence supporting its sufficiency for adult fertility. Dev Biol 2006, 298:149-154.

13. Faddy M, Gosden R: Let's not ignore the statistics. Biol Reprod 2009, 81:231-232.

14. Santiquet $N$, Vallières $L$, Pothier $F$, Sirard $M A$, Robert $C$, Richard F Transplanted bone marrow cells do not provide new oocytes but rescue fertility in female mice following treatment with chemotherapeutic agents. Cell Reprogr 2012, 14:123-129.

15. Kerr JB, Duckett R, Myers M, Britt KL, Mladenovska T, Findlay JK: Quantification of healthy follicles in the neonatal and adult mouse ovary: evidence for maintenance of primordial follicle supply. Reproduction 2006, 132:95-109.

16. Eggan K, Jurga S, Gosden R, Min IM, Wagers AJ: Ovulated oocytes in adult mice derive from non-circulating germ cells. Nature 2006, 441:1109-1114.

17. Liu Y, Wu C, Lyu Q, Yang D, Albertini DF, Keefe DL, Liu L: Germline stem cells and neo-oogenesis in the adult human ovary. Dev Biol 2007, 306:112-120.

18. Byskov AG, Høyer PE, Yding Andersen C, Kristensen SG, Jespersen A, Møllgard K: No evidence for the presence of oogonia in the human ovary after their final clearance during the first two years of life. Hum Reprod 2011, 26:2129-2139.

19. Kerr JB, Brogan L, Myers M, Hutt K, Mladenovska T, Ricardo S, Hamza K, Scott CL, Strasser A, Findlay JK: The primordial follicle reserve is not renewed after chemical or $\gamma$-irradiation mediated depletion. Reproduction 2012, 143:469-476

20. Harley CB: Telomere loss: mitotic clock or genetic time bomb? Mutat Res 1991, 256:271-282. 
21. Wright WE, Piatyszek MA, Rainey WE, Byrd W, Shay JW: Telomerase activity in human germline and embryonic tissues and cells. Dev Genet 1996, 8:173-179.

22. Kinugawa C, Murakami T, Okamura K, Yajima A: Telomerase activity in normal ovaries and premature ovarian failure. Tohoku J Exp Med 2000, 190:321-328.

23. Parrott JA, Kima G, Skinner MK: Expression and action of kit ligand/stem cell factor in normal human and bovine ovarian surface epithelium and ovarian cancer. Biol Reprod 2000, 62:1600-1609.

24. Bowen NJ, Walker LD, Matyunina LV, Logani S, Totten KA, Benigno BB, McDonald JF: Gene expression profiling supports the hypothesis that human ovarian surface epithelia are multipotent and capable of serving as ovarian cancer initiating cells. BMC Med Genomics 2009, 2:71.

25. Paik DY, Janzen DM, Schafenacker AM, Velasco VS, Shung MS, Cheng D, Huang J, Witte ON, Memarzadeh S: Stem-like epithelial cells are concentrated in the distal End of the fallopian tube: a site for injury and serous cancer initiation. Stem Cells 2012, 30:2487-2497.

26. Kurman RJ, Shih IM: The origin and pathogenesis of epithelial ovarian cancer: a proposed unifying theory. Am J Surg Pathol 2010, 34:433-443.

27. Virant-Klun I, Skutella T, Cvjeticanin B, Stimpfel M, Sinkovec J: Serous papillary adenocarcinoma possibly related to the presence of primitive oocyte-like cells in the adult ovarian surface epithelium: a case report. J Ovarian Res 2011, 4:13.

28. Bukovsky A, Keenan JA, Caudle MR, Wimalasena J, Upadhyaya NB, Van Meter SE: Immunohistochemical studies of the adult human ovary: possible contribution of immune and epithelial factors to folliculogenesis. Am J Reprod Immunol 1995, 33:323-340.

29. Bukovsky A, Caudle MR, Svetlikova M, Upadhyaya NB: Origin of germ cells and formation of new primary follicles in adult human ovaries. Reprod Biol Endocrinol 2004, 2:20. http://www.rbej.com/content/2/1/20.

30. Bukovsky A, Svetlikova M, Caudle MR: Oogenesis in cultures derived from adult human ovaries. Reprod Biol Endocrinol 2005, 3:17.

31. Bukovsky A, Caudle MR, Svetlikova M, Wimalasena J, Ayala ME, Dominguez $\mathrm{R}$ : Oogenesis in adult mammals, including humans: a review. Endocrine 2005, 26:301-316.

32. Bukovsky A, Virant-Klun I: Adult stem cells in the human ovary. In Stem cells in reproductive medicine: basic science \& therapeutic potential. Edited by Simon C, Pellicer A. London: Informa Healthcare; 2007:53-69.

33. Bukovsky A: How Can female germline stem cells contribute to the physiological Neo-oogenesis in mammals and Why menopause occurs? Microsc Microanal 2011, 17:498-505.

34. Bukovsky A: Ovarian stem cell niche and follicular renewal in mammals. Anat Rec (Hoboken) 2011, 294:1284-1306.

35. Bukovsky A, Caudle MR: Immunoregulation of follicular renewal, selection, POF, and menopause in vivo, vs. neo-oogenesis in vitro, POF and ovarian infertility treatment, and a clinical trial. Reprod Biol Endocrinol 2012, 10:97. http://www.rbej.com/content/10/1/97.

36. Bukovsky A, Caudle MR: Immune physiology of the mammalian ovary-a review. Am J Reprod Immunol 2008, 59:12-26.

37. Zhang D, Fouad H, Zoma WD, Salama SA, Wentz MJ, Al-Hendy A: Expression of stem and germ cell markers within nonfollicle structures in adult mouse ovary. Reprod Sci 2008, 15:139-146.

38. Virant-Klun I, Zech N, Rozman P, Vogler A, Cvjeticanin B, Klemenc P, Malicev E, Meden-Vrtovec $\mathrm{H}$ : Putative stem cells with an embryonic character isolated from the ovarian surface epithelium of women with no naturally present follicles and oocytes. Differentiation 2008, 76:843-856.

39. Virant-Klun I, Rozman P, Cvjeticanin B, Vrtacnik-Bokal E, Novakovic S, Rülicke T: Parthenogenetic embryo-like structures in the human ovarian surface epithelium cell culture in postmenopausal women with no naturally present follicles and oocytes. Stem Cells Dev 2008, 18:137-149.

40. Celik O, Esrefoglu M, Hascalik S, Gul M, Tagluk ME, Elter K, Aydin E: Use of porcine small intestinal submucosa to reconstruct an ovarian defect. Int J Gynecol Obstet 2009, 106:218-222.

41. Parte S, Bhartiya D, Telang J, Daithankar V, Salvi V, Zaveri K, Hinduja I: Detection, characterization, and spontaneous differentiation in vitro of very small embryonic-like putative stem cells in adult mammalian ovary. Stem Cells Dev 2011, 20:1451-1464.

42. Virant-Klun I, Skutella T, Stimpfel M, Sinkovec J: Ovarian surface epithelium in patients with severe ovarian infertility: a potential source of cells expressing markers of pluripotent/multipotent stem cells. J Biomed Biotechnol 2011, 2011:1-12
43. Bhartiya D, Sriraman K, Gunjal P, Modak H: Gonadotropin treatment augments postnatal oogenesis and primordial follicle assembly in adult mouse ovaries? J Ovarian Res 2012, 5:32.

44. Niikura Y, Niikura T, Tilly JL: Aged mouse ovaries possess rare premeiotic germ cells that can generate oocytes following transplantation into a young host environment. Aging (Albany NY) 2009, 1:971-978.

45. Zou K, Yuan Z, Yang Z, Luo H, Sun K, Zhou L, Xiang J, Shi L, Yu Q, Zhang Y, et al: Production of offspring from a germline stem cell line derived from neonatal ovaries. Nature Cell Biol 2009, 11:631-636.

46. Bhartiya D, Sriraman K, Parte S: Stem cell interaction with somatic niche may hold the key to fertility restoration in cancer patients. Obstet Gynecol Int 2012, 2012:921082.

47. White YA, Woods DC, Takai Y, Ishihara O, Seki H, Tilly JL: Oocyte formation by mitotically active germ cells purified from ovaries of reproductive-age women. Nat Med 2012, 18:413-421.

48. Hayashi K, Ogushi S, Kurimoto K, Shimamoto S, Ohta H, Saitou M: Offspring from oocytes derived from in vitro primordial germ cell-like cells in mice. Science 2012, 338(6109):971-975.

49. Ratajczak MZ, Zuba-Surma EK, Shin DM, Ratajczak J, Kucia M: Very small embryonic-like (VSEL) stem cells in adult organs and their potential role in rejuvenation of tissues and longevity. Exp Gerontol 2008, 43:1009-1017.

50. Kucia M, Reca R, Campbell FR, Zuba-Surma E, Majka M, Ratajczak J, Ratajczak $\mathrm{MZ}$ : A population of very small embryonic-like (VSEL) CXCR4 (+) SSEA-1 (+)Oct-4+ stem cells identified in adult bone marrow. Leukemia 2006, 20:857-869.

51. Bukovsky A, Caudle MR, Virant-Klun I, Gupta SK, Dominguez R, Svetlikova M, Xu F: Immune physiology and oogenesis in fetal and adult humans, ovarian infertility, and totipotency of adult ovarian stem cells. Birth Defects Res C Embryo Today 2009, 87:64-89.

52. Pacchiarotti J, Maki C, Ramos T, Marh J, Howerton K, Wong J, Pham J, Anorve S, Chow YC, Izadyar F: Differentiation potential of germ line stem cells derived from the postnatal mouse ovary. Differentiation 2010, 79:159-170.

53. Motta MP, Makabe S: Development of the ovarian surface and associated germcells in the human fetus. A correlated study by scanning and transmission electron microscopy. Cell Tissue Res 1982, 226:493-510.

54. Baas T: Repowering the ovary. Science-Business eXchange 2012, 5:4-6.

doi:10.1186/1477-7827-10-112

Cite this article as: Celik et al:: Germline cells in ovarian surface epithelium of mammalians: a promising notion. Reproductive Biology and Endocrinology 2012 10:112.

\section{Submit your next manuscript to BioMed Central and take full advantage of:}

- Convenient online submission

- Thorough peer review

- No space constraints or color figure charges

- Immediate publication on acceptance

- Inclusion in PubMed, CAS, Scopus and Google Scholar

- Research which is freely available for redistribution

Submit your manuscript at www.biomedcentral.com/submit
C) Biomed Central 